\title{
Termi-Luc: a versatile assay to monitor full-protein release from ribosomes
}

\author{
DENIS SUSOROV, SHAWN EGRI, and ANDREI A. KOROSTELEV \\ RNA Therapeutics Institute, University of Massachusetts Medical School, Worcester, Massachusetts 01605, USA
}

\begin{abstract}
Termination of protein biosynthesis is an essential step of gene expression, during which a complete functional protein is released from the ribosome. Premature or inefficient termination results in truncated, nonfunctional, or toxic proteins that may cause disease. Indeed, more than $10 \%$ of human genetic diseases are caused by nonsense mutations leading to premature termination. Efficient and sensitive approaches are required to study eukaryotic termination mechanisms and to identify potential therapeutics that modulate termination. Canonical radioactivity-based termination assays are complex, report on a short peptide release, and are incompatible with high-throughput screening. Here we describe a robust and simple in vitro assay to study the kinetics of full-protein release. The assay monitors luminescence upon release of nanoluciferase from a mammalian pretermination complex. The assay can be used to record time-progress curves of protein release in a high-throughput format, making it optimal for studying release kinetics and for high-throughput screening for small molecules that modulate the efficiency of termination.
\end{abstract}

Keywords: luminescence; protein release; translation termination

\section{INTRODUCTION}

Translation termination occurs when the ribosome recognizes a stop codon in the A site. In eukaryotes, stop codons UAA, UGA, and UAG are decoded by release factor eRF1 aided by GTPase eRF3 (Hellen 2018). Termination defines the lengths of all cellular proteins and is therefore a critical step of gene expression. Indeed, many genetic diseases are caused by nonsense mutations, which result in premature release of truncated proteins that can be nonfunctional or toxic (Mort et al. 2008). Termination is regulated by sequence and structure of the mRNA downstream from the stop codon (Brar 2016; Cridge et al. 2018) and by interactions between release factors and other proteins (Kashima et al. 2006; Ivanov et al. 2016; Mikhailova et al. 2017). For example, poly(A)-binding protein (PABP) and the position of a stop codon relative to the poly $(A)$ tail affect the efficiency of termination, and are associated with the severity of nonsense-mutation diseases (Mort et al. 2008; Wu et al. 2019). Mechanistic understanding of termination, including accuracy, efficiency, and dependence on mRNA sequence and protein factors requires a robust quantitative termination assay. Furthermore, assays amenable to high-throughput drug screening are needed to

Corresponding author: andrei.korostelev@umassmed.edu Article is online at http://www.rnajournal.org/cgi/doi/10.1261/rna. 076588.120. Freely available online through the RNA Open Access option. identify drugs that modulate or prevent termination at premature nonsense codons.

In vitro biochemical assays have extensively informed our understanding of bacterial translation termination. For example, kinetic assays have been used to characterize the efficiency of release factors on different codons (Freistroffer et al. 2000; Hoernes et al. 2018), how release factor mutations affect termination (Nakamura and Ito 1998), and how antibiotics inhibit bacterial termination (Youngman et al. 2007; Svidritskiy et al. 2013). They have also revealed that the efficiency of termination depends on the length of the peptidyl moiety attached to tRNA, suggesting that longer peptides are more efficient than single aminoacyl-tRNA (Zavialov et al. 2001; Alkalaeva et al. 2006). Furthermore, full-protein folding at the end of termination might affect the efficiency of release (Goldman et al. 2015). Nevertheless, release of full-length protein has not been extensively studied using canonical in vitro assays in bacterial systems. Eukaryotic in vitro termination assays are even less accessible. A tour de force mammalian in vitro termination assay requires more than a dozen translation factors, which must be purified and assembled into a pretermination complex (Alkalaeva et al. 2006; Eyler and Green 2011; Ng et al. 2018). These assays

(C) 2020 Susorov et al. This article, published in RNA, is available under a Creative Commons License (Attribution-NonCommercial 4.0 International), as described at http://creativecommons.org/licenses/ by-nc/4.0\%. 
usually use an mRNA coding for a short peptide (4-6 amino acids) to monitor release of a radioactively labeled peptide (Alkalaeva et al. 2006). Thus, the kinetics of fulllength protein release from eukaryotic ribosomes remains unaddressed. Radioactive labeling is a major limitation of termination assays, as it makes kinetic measurements cumbersome and renders the assays unsuitable for highthroughput, small-molecule screening.

We have developed a robust assay to measure the release of full-length protein from mammalian ribosomes. The assay measures release of a 19-kDa nanoluciferase, whose carboxy-terminal tail must fold into the rest of the et al. 2016). Nanoluciferase has several advantages over the larger firefly luciferase, which is commonly used as a reporter. Compared to firefly luciferase, nanoluciferase luminescence is at least an order of magnitude greater, more stable over time, and less dependent on temperature and $\mathrm{pH}$ (England et al. 2016). Finally, nanoluciferase requires a luciferin-like substrate (furimazine) but does not require ATP, which can chelate $\mathrm{Mg}^{2+}$ and may interfere with translation assays and high-throughput screens for small-molecule modulators of translation (Auld and Inglese 2004).

Our assay can be used to record time-progress curves of protein release by release factors and puromycin, an aminoacyl-tRNA mimic that stimulates protein release by covalently attaching to its carboxyl terminus. Release factor protein to form an active catalytic domain (Fig. 1A; Dixon

eRF1 induces efficient release, which can be inhibited by mutant release factor or small-molecule inhibitor G418. Finally, we demonstrate that the sensitive readout in a microplate luminescence reader can be used to efficiently monitor the inhibition of release, making the assay amenable to high-throughput screens to identify or optimize therapeutics.

\section{RESULTS AND DISCUSSION}

Our assay is based on the premise that the nascent tRNAbound nanoluciferase is inactive because its carboxyterminal region-essential for luminescence (Dixon et al. 2016) - is occluded by the ribosomal polypeptide tunnel (Fig. 1A,B; Jha and Komar 2011). We hypothesized that the release of nanoluciferase results in the appearance of luminescence upon fast (millisecond range) folding of nanoluciferase into an active state (Dixon et al. 2016). Indeed, in rabbit reticulocyte lysates, nanoluciferase mRNA with a stop codon produced luminescence, but a nanoluciferase mRNA without a stop codon (to prevent protein release) produced no luminescence (Fig. 1C). This result echoes a study of firefly luciferase, showing that the corresponding mRNA without a stop codon produces no luminescence (Kolb et al. 1994). Adding puromycin to the stalled nonstop translation complexes stimulates luminescence, indicating the release of nanoluciferase (Fig. 1C).

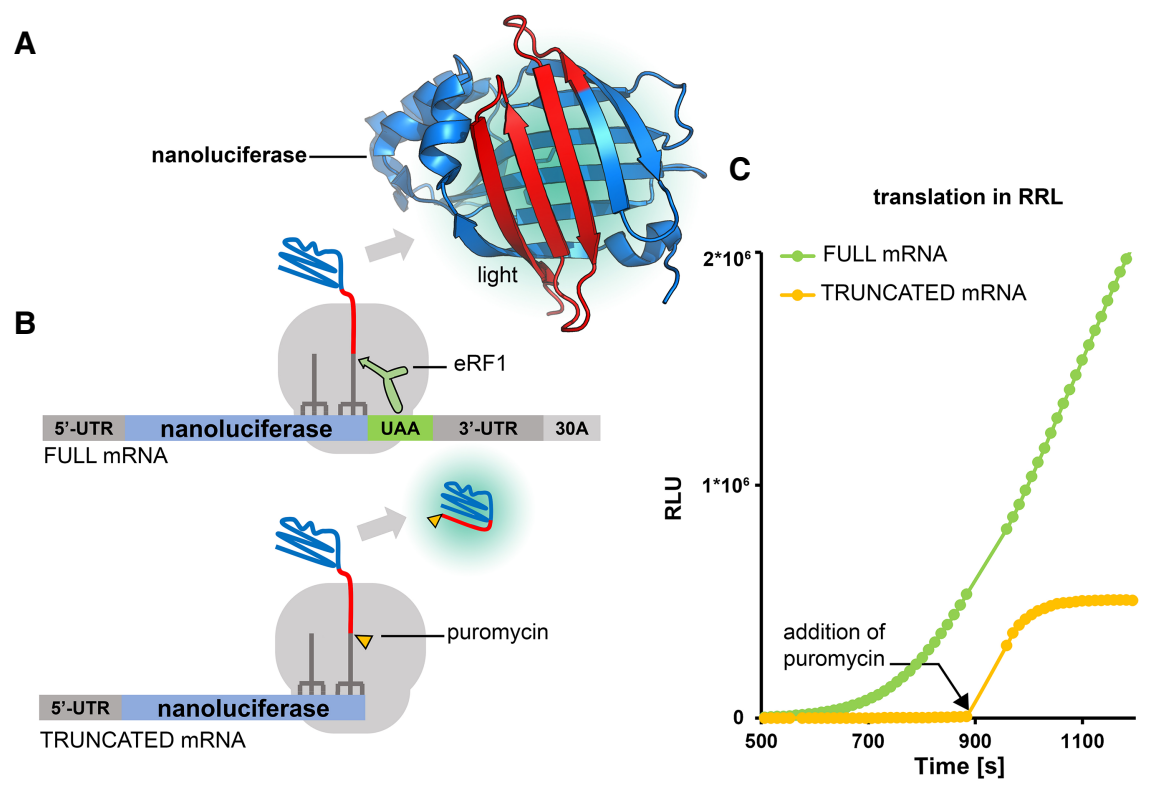

FIGURE 1. The schematic of the nanoluciferase pretermination complex. (A) Crystal structure of nanoluciferase. Carboxy-terminal amino acids (129-169; red) likely occupy the polypeptide tunnel of the ribosome in the pretermination complex. (B) mRNA constructs used to monitor nanoluciferase release. (C) Progress of nanoluciferase mRNA translation in rabbit reticulocyte lysate: stop codon containing mRNA is shown in green and nonstop mRNA translation followed by addition of puromycin is shown in yellow (relative luminescence units [RLUs] are on the $y$-axis).
We next optimized the purification of pretermination complexes on an in vitro transcribed full-length nanoluciferase mRNA with a UAA stop codon, $\beta$-globin $5^{\prime}$ - and $3^{\prime}$-UTRs, and a 30-nt poly(A) tail (Fig. 1B). Translation of mRNA was initiated in the commercial nuclease-treated rabbit reticulocyte lysates using a standard set of reagents (Fig. 2A; see Materials and Methods). To stall translation on the stop codon without releasing the protein, we added catalytically inactive eRF1 ${ }^{A G O}$ (catalytic GGO motif mutated to AGQ) (Frolova et al. 1999; Brown et al. 2015). The stalled 805 was purified by sucrose gradient fractionation (Fig. 2A; see Materials and Methods), which removes eRF1 ${ }^{A G O}$ (Shao et al. 2016) and results in a pretermination $80 \mathrm{~S}$ complex with nanoluciferase-tRNA in the $P$ site and a vacant $A$ site containing a stop codon (Fig. 1A).

We tested whether adding purified recombinant eRF1 or puromycin to purified pretermination complexes 


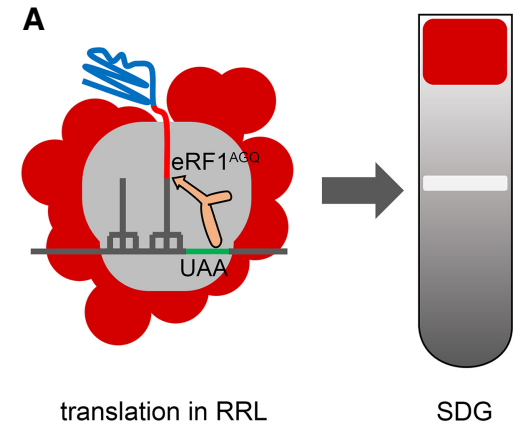

$$
\text { B }
$$

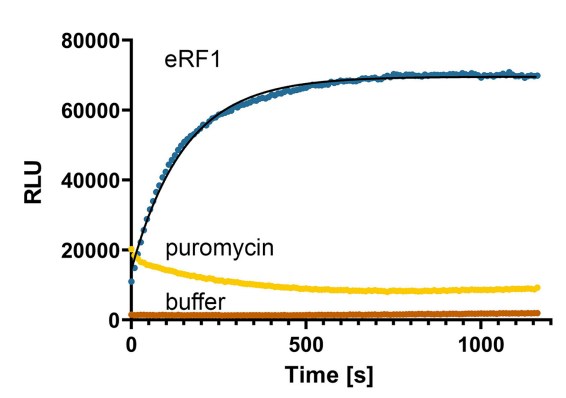

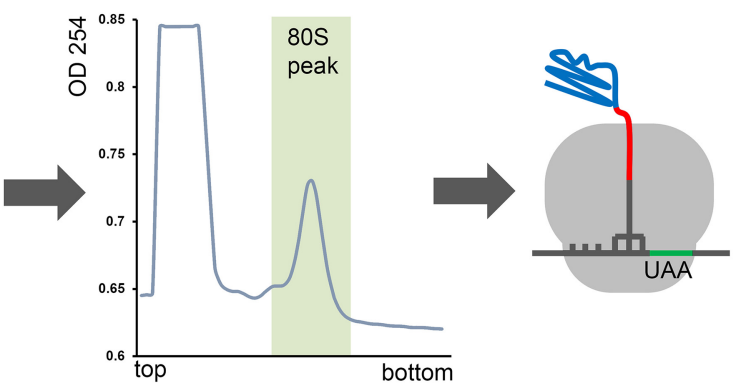

gradient fractionation

purified complex

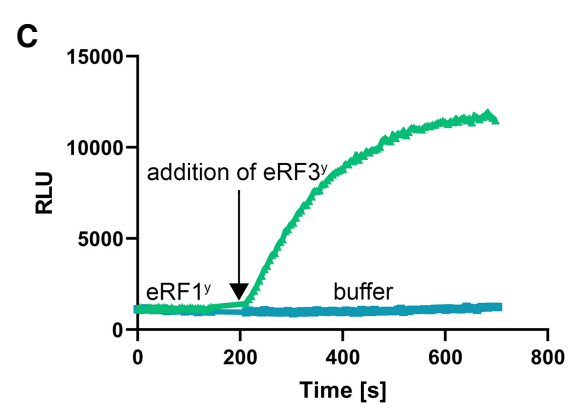

FIGURE 2. Preparation of the $80 \mathrm{~S}$ pretermination complex and nanoluciferase release kinetics. (A) Purification of the 80S pretermination nanoluciferase complex stalled on the stop codon in rabbit reticulocyte lysate, using sucrose gradient fractionation. (B) Time-progress curves showing luminescence (in relative luminescence units [RLUs]) of the $80 \mathrm{~S}$ pretermination nanoluciferase complex upon treatment with recombinant human eRF1 (blue), puromycin (yellow), or buffer (negative control, brown). (C) Time-progress curves showing luminescence (in relative luminescence units [RLUs]) of the $80 \mathrm{~S}$ pretermination nanoluciferase complex incubated with recombinant yeast eRF1y and treated by yeast eRF3y (green) or buffer (negative control, blue). Exponential fits are shown by black lines. An amount of $20 \mu \mathrm{L}$ reactions were performed in a microplate reader.

would stimulate release of nanoluciferase and luminescence. The reactions were carried out in $20 \mu \mathrm{L}$ volumes using a microplate luminescence reader. Indeed, both eRF1 and puromycin stimulated release of nanoluciferase. 0.6 $\mu \mathrm{M}$ human eRF1 released nanoluciferase with an apparent rate constant of $\sim 0.4 \mathrm{~min}^{-1}$ (obtained by single-exponential fitting; Fig. 2B), similar to rates observed for human eRF1 on pretermination complexes assembled in vitro (Alkalaeva et al. 2006). Puromycin released nanoluciferase faster than eRF1, but the luminescence signal over time remained low (Fig. 2B), suggesting the puromycin adduct may interfere with nanoluciferase activity. Importantly, the pretermination complexes do not spontaneously release nanoluciferase (buffer control; Fig. 2B) in contrast to the complexes with short peptides showing substantial background release that is only a few-fold slower than eRF1-induced release (Alkalaeva et al. 2006). High stability of the nanoluciferase pretermination complex is an excellent property to derive accurate kinetic parameters.

Translation termination in eukaryotes is accelerated by the GTPase protein eRF3 (Zhouravleva et al. 1995; Alkalaeva et al. 2006; Eyler et al. 2013). We therefore asked whether eRF3 synergizes with eRF1 in our nanoluciferase release assay. We used yeast eRF1y and eRF3y, which were shown to function in heterologous eukaryotic systems ( $\mathrm{Ng}$ et al. 2018). We adjusted eRF1y concentra- tion to $0.01 \mu \mathrm{M}$ so that nanoluciferase release was negligible (Fig. 2C). Addition of $0.05 \mu \mathrm{M}$ eRF3y $\bullet$ GTP resulted in fast increase in luminescence, in keeping with efficient protein release by $\mathrm{eRF} 1 \bullet \mathrm{eRF} 3 \bullet \mathrm{GTP}$ termination complex (Fig. 2C).

We next tested whether our in vitro release assay is suitable for characterizing termination inhibitors. As an example of a competitive inhibitor, we used the catalytically inactive $\mathrm{eRF}^{\mathrm{AGQ}}$. As expected, release was substantially slower in the presence of equimolar amounts of human eRF1 and eRF1 ${ }^{\mathrm{AGO}}$ than eRF1 alone (0.6 $\mu \mathrm{M}$; Fig. 3A).

We then asked whether $\mathrm{G} 418$, an aminoglycoside that induces stop codon readthrough (Dabrowski et al. 2018; Wangen and Green 2020), inhibits nanoluciferase release. Stop codon readthrough by $\mathrm{G} 418$ and other aminoglycosides could be primarily due to (i) misreading of the stop codon by a near-cognate tRNA (Prokhorova et al. 2017); (ii) inhibition of eRF1; or (iii) a combination of (i) and (ii). On bacterial ribosomes, aminoglycosides both induce miscoding (Davies et al. 1965) and inhibit translation termination (Youngman et al. 2007). But bacterial release factors RF1 and RF2 and their interactions with the stop codons (Korostelev et al. 2008, 2010; Laurberg et al. 2008; Weixlbaumer et al. 2008) substantially differ from those in eukaryotic eRF1-bound termination complexes (Brown et al. 2015; Matheisl et al. 2015). It therefore remains 
A
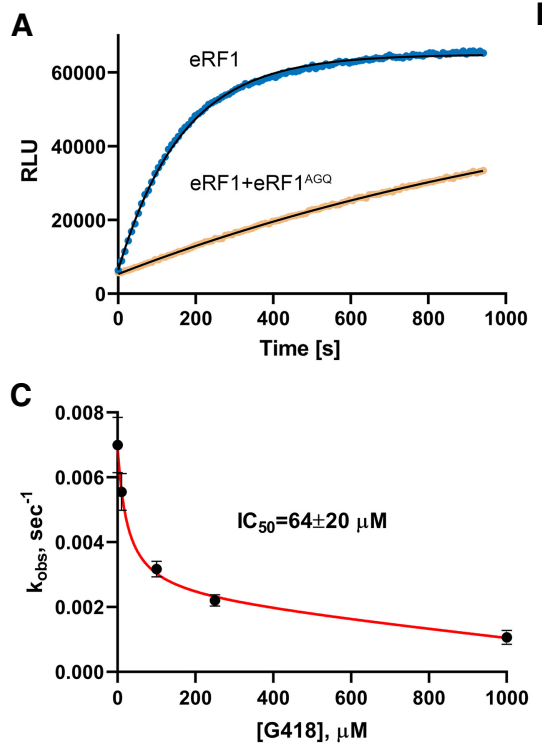

B

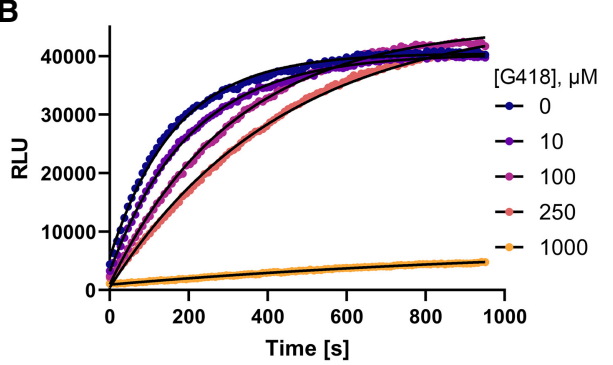

D

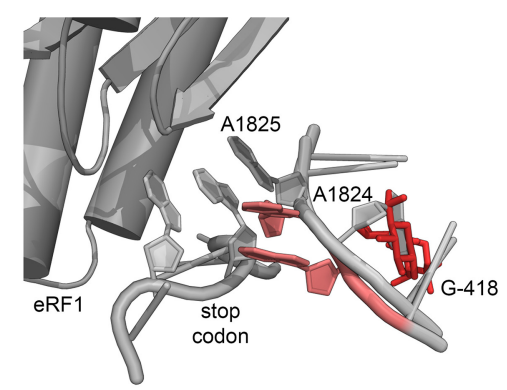

FIGURE 3. Competitive inhibition of eRF1-induced release of nanoluciferase from purified $80 \mathrm{~S}$ pretermination complexes. (A) Luminescence in the presence of wild-type eRF1 or equimolar amounts of wild-type eRF1 and catalytically inactive eRF1AGQ $(0.6 \mu M)$. (B) Luminescence in the presence of wild-type eRF1 and different concentrations of G418. (C) Dependence of catalytic rates ( $\left.k_{\text {obs }}\right)$ for eRF1-mediated release of nanoluciferase on G418 concentration. $I C_{50}$ was determined by hyperbola fitting (red) of $k_{\text {obs }}$ values obtained at different concentrations of G418 and $0.6 \mu \mathrm{M}$ human eRF1. Error bars represent standard deviation of the mean $(n=3)$. (D) Alignment of G418-bound 80S decoding center (red; Prokhorova et al. 2017) with that of eRF1-bound 80 S termination complex carrying a UAA stop codon (gray; Brown et al. 2015) shows steric clash of G418 with A1824.

unclear whether G418 efficiently inhibits eukaryotic termination.

We found that $\mathrm{G} 418$ inhibited eukaryotic translation termination with an $\mathrm{IC}_{50}$ of $64 \pm 20 \mu \mathrm{M}$ (Fig. 3B,C), similar to that for bacterial termination inhibition by paromomycin ( $35 \mu \mathrm{M}$; Youngman et al. 2007). Inhibition of termination is consistent with the structural mechanism of G418 binding to the decoding center of the eukaryotic ribosome (Prokhorova et al. 2017) and inducing the bulged conformations of nucleotides A1824-A1825 (18S rRNA nucleotides of $H$. sapiens ribosome; corresponding to A1492 and $\mathrm{A} 1493$ of E. coli ribosome; Fig. 3D). In this conformation, the adenosines would clash with the U-turn conformation of the stop codon. Furthermore, G418 would clash with A1824 docking within helix 44 upon eRF1 binding (Fig. 3D). These data suggest that modest inhibition of eRF1 may synergize with the ability of G418 to induce decoding of the stop codon by a near-stop tRNA, explaining the readthrough.

\section{Conclusions}

We have developed a robust and versatile translation termination assay. The luminescence-based assay is straightforward, more efficient than assays that measure release of radioactive peptides, and suitable for studies of full-protein release on ribosomes from almost any organism. Our assay can be used to study the regulation of translation termination, including how the context of a stop codonthat is, sequences or structures surrounding the stop codon-affects termination. Indeed, nanoluciferase can report on release from mRNAs with and without a $3^{\prime}$-UTR (Figs. 1 and 2), indicating that varying stop codon identities and downstream sequences can be tested. While our manuscript was under review, firefly luciferase was reported to capture the effects of different 3'-UTR sequences and other factors on termination in cell-free translation (Lashkevich et al. 2020), highlighting that distinct luciferase reporters can be harnessed for quantitative termination analyses. Furthermore, sequences upstream of the stop codon can be introduced in our method to study the proposed effects of the ORF on termination (Pierson et al. 2016). The last $\sim 13$ amino acid residues of nanoluciferase are essential for activity, and nanoluciferase retains luminescence upon carboxy-terminal extension (Dixon et al. 2016). Because the polypeptide tunnel can occlude $\sim 40$ amino acids (Jha and Komar 2011), the nanoluciferase carboxyl terminus can be extended by up to 25 varying amino acid sequences to study the effects of the mRNA preceding the stop codon. Lastly, the ability to measure termination in a microplate reader makes the assay suitable for high-throughput screens to identify termination modulators and potential therapeutics for genetic diseases caused by nonsense mutations.

\section{MATERIALS AND METHODS}

\section{Plasmids and mRNA constructs}

DNA plasmids encoding nanoluciferase constructs were designed as follows. Nanoluciferase sequence from pNL1.1[Nluc] Vector (Promega) was inserted into pUC57(Kan) plasmid (GenScript), flanked by $\beta$-globin $5^{\prime}$ - and $3^{\prime}$-UTRs. Templates for in vitro transcription were generated using PCR. For FULL mRNA, a pair of primers annealing to the globin UTRs was used: the forward primer (ttttTAATACGACTCACTATAGaca cttgcttttgacacaactgtg) containing a T7-promoter and the reverse primer with a 30-nt poly-T-stretch (tttttttttttttttttttttttttGC AATGAAAATAAATTTCCTTTATTAGCC). For the NO-STOP 
mRNA, a reverse primer annealing to the $3^{\prime}$ end of the nanoluciferase coding sequence was used (CGCCAGAATGCGTTCGCAC). In vitro transcription with recombinant T7 RNA polymerase was done as described (Alkalaeva et al. 2006); transcription products were precipitated with $2.5 \mathrm{M} \mathrm{LiCl}$, washed with $80 \%$ ethanol, and dissolved in deionized water. Concentrations of mRNAs were determined using Nanodrop 2000 (Thermo Fisher).

\section{Purification of human eRF1, eRF1 ${ }^{A G O}$, and yeast eRF1 and eRF3}

His-tagged recombinant proteins were expressed in E. coli and purified as described (Frolova et al. 1998, 2000) for human eRF1, eRF1 ${ }^{A G Q}$, and in Eyler et al. (2013) for yeast eRF1 and eRF3.

\section{In vitro translation reaction in $\mathrm{RRL}$}

Reaction mixture containing $50 \%$ of nuclease-treated rabbit reticulocyte lysate (RRL) (Promega) was supplemented with $30 \mathrm{mM}$ Hepes- $\mathrm{KOH}(\mathrm{pH}=7.5), 50 \mathrm{mM} \mathrm{KOAc}, 1.0 \mathrm{mM} \mathrm{Mg}(\mathrm{OAc})_{2}$, $0.2 \mathrm{mM}$ ATP and GTP, $0.04 \mathrm{mM}$ of 20 amino acids (Promega), and $2 \mathrm{mM}$ DTT. Nanoluciferase substrate furimazine (Promega) was added to the mixture at $1 \%$. An amount of $10 \mu \mathrm{L}$ aliquots of the mixture were placed in a 384-well plate (Corning Low Volume White Round Bottom) and incubated at $30^{\circ} \mathrm{C}$ for $5 \mathrm{~min}$ in a microplate reader (Tecan INFINITE M1000 PRO). Translation reactions were started by addition of mRNA (final concentration $10 \mathrm{ng} / \mu \mathrm{L}$ ) and the luminescence signal was recorded. At $900 \mathrm{sec}, 1 \mu \mathrm{L}$ of water (control) or puromycin solution in water were added $(100 \mu \mathrm{M}$ final concentration in the reaction). The resulting data were processed in Microsoft Excel.

\section{Preparation of the pretermination complex and rabbit reticulocyte lysate}

Purification of pretermination complexes was done from $1 \mathrm{~mL}$ translation mixtures described above. To stall translation progress at the stop codon, reaction mixture was preincubated with $1 \mu \mathrm{M}$ eRF1 ${ }^{A G Q}$ at $30^{\circ} \mathrm{C}$ for 10 min followed by the addition of FULL mRNA to the final concentration of $8 \mu \mathrm{g} / \mathrm{mL}$ and incubation at $30^{\circ} \mathrm{C}$ for $25 \mathrm{~min}$. Using this mRNA concentration resulted in predominant formation of monosomic 805 complexes (see representative sucrose gradient profile in Fig. 2A). Then, KoAC concentration was adjusted to $300 \mathrm{mM}$ and the mixture was layered on a $10 \%-35 \%$ linear gradient of sucrose in buffer $A(50$ $\mathrm{mM}$ Hepes- $\mathrm{KOH}, \mathrm{pH}=7.5,7.5 \mathrm{mM} \mathrm{Mg}(\mathrm{OAc})_{2}, 300 \mathrm{mM} \mathrm{KOAc}$, $2 \mathrm{mM}$ DTT), prepared using the Gradient Profiler system (Biocomp). The gradients were centrifuged in SW-41 Ti (Beckman Coulter) rotor at 40,000g for 2.5 h (Beckman Coulter Optima TLX). Gradient Profiler was used to collect fractions corresponding to the monosomic 80S-mRNA ribosomes. The sample was concentrated using Amicon Ultra-15 Centrifugal Filter Units (MilliporeSigma), yielding $\sim 50 \mathrm{nM}$ ribosome (one $\mathrm{A} 260$ unit= 20 nM 80S ribosomes) using Nanodrop 2000 (Thermo Fisher). Ribosome solution was aliquoted, flash-frozen in liquid nitrogen, and stored at $-80^{\circ} \mathrm{C}$. After $5 \mathrm{mo}$ of storage, the complexes retained $\sim 70 \%$ of the initial signal level (compare Fig. 3A,B).

\section{Kinetic reactions with purified nanoluciferase- ribosome complexes}

$80 \mathrm{~S}$ solution was diluted to $\sim 15 \mathrm{nM}$ with buffer $\mathrm{B}$ ( $50 \mathrm{mM}$ Hepes$\mathrm{KOH}, \mathrm{pH}=7.5,0.25 \mathrm{mM}$ spermidine, $2 \mathrm{mM}$ DTT), supplemented with $1 \%$ nanoluciferase substrate (Promega), aliquoted $(20 \mu \mathrm{L})$, and placed in a 384-well plate. The samples were incubated at $30^{\circ} \mathrm{C}$ for $5 \mathrm{~min}$ in the absence/presence of $0.6 \mu \mathrm{M}$ eRF1 $1^{\mathrm{AGQ}}$ or 10-1000 $\mu$ M G418 (Gold Biotechnology) to test inhibition by the eRF1 mutant or G418. Release reaction was started by the addition of $0.6 \mu \mathrm{M}$ human eRF1, $100 \mu \mathrm{M}$ puromycin, or $0.01 \mu \mathrm{M}$ yeast eRF1 ${ }^{y}$ followed by the addition of $0.05 \mu \mathrm{M}$ yeast eRF3 ${ }^{\mathrm{y}}$ with $0.2 \mathrm{mM} \mathrm{GTP}$, and luminescence was recorded. Buffer $\mathrm{C}$ (20 mM Tris- $\mathrm{HCl}, \mathrm{pH}=7.5,100 \mathrm{mM} \mathrm{KCl}, 6$ mM 2-Mercaptoethanol, $10 \%$ glycerol) or water were used as a negative control. The data were plotted and fitted in GraphPad Prism 8 using single-exponential fits to obtain $k_{\text {obs }}$ values, and in Gnuplot using hyperbola fitting to obtain $\mathrm{IC}_{50}$.

\section{Structural analysis and visualization}

Structural analysis and visualization were done in PyMol (Schrödinger) using PDB 5IBO for nanoluciferase (S Lovell, in prep.), PDB 5NDG for G418-bound yeast ribosome (Prokhorova et al. 2017), and PDB 3JAG for eRF1-bound mammalian ribosome (Brown et al. 2015). Yeast and mammalian ribosomes were aligned by $18 \mathrm{~S}$ rRNA. All figures were assembled in Adobe Photoshop.

\section{ACKNOWLEDGMENTS}

We thank Darryl Conte Jr., Dmitri N. Ermolenko, and members of the Korostelev laboratory for discussions and comments on the manuscript. This study was supported by National Institutes of Health (NIH) grant R35 GM127094 (to A.A.K.).

Author contributions: D.S. and A.A.K. conceptualized the idea. D.S. and S.E. carried out the methodology and investigation. D.S., S.E., and A.A.K. analyzed the data. A.A.K. provided resources. D.S. and A.A.K. wrote the original draft. All authors contributed to reviewing and editing the manuscript. D.S. provided visualization, A.A.K. the supervision, and A.A.K. the funding acquisition.

Received May 28, 2020; accepted August 11, 2020.

\section{REFERENCES}

Alkalaeva EZ, Pisarev AV, Frolova LY, Kisselev LL, Pestova TV. 2006. In vitro reconstitution of eukaryotic translation reveals cooperativity between release factors eRF1 and eRF3. Cell 125: 1125-1136. doi:10.1016/j.cell.2006.04.035

Auld DS, Inglese J. 2004. Interferences with luciferase reporter enzymes. http://www.ncbi.nlm.nih.gov/pubmed/27478246

Brar GA. 2016. Beyond the triplet code: context cues transform translation. Cell 167: 1681-1692. doi:10.1016/j.cell.2016 .09 .022

Brown A, Shao S, Murray J, Hegde RS, Ramakrishnan V. 2015. Structural basis for stop codon recognition in eukaryotes. Nature 524: 493-496. doi:10.1038/nature14896 
Cridge AG, Crowe-Mcauliffe C, Mathew SF, Tate WP. 2018. Eukaryotic translational termination efficiency is influenced by the $3^{\prime}$ nucleotides within the ribosomal mRNA channel. Nucleic Acids Res 46: 1927-1944. doi:10.1093/nar/gkx1315

Dabrowski M, Bukowy-Bieryllo Z, Zietkiewicz E. 2018. Advances in therapeutic use of a drug-stimulated translational readthrough of premature termination codons. Mol Med 24: 25. doi:10.1186/ s10020-018-0024-7

Davies J, Gorini L, Davis BD. 1965. Misreading of RNA codewords induced by aminoglycoside antibiotics. Mol Pharmacol 1: 93-106.

Dixon AS, Schwinn MK, Hall MP, Zimmerman K, Otto P, Lubben TH, Butler BL, Binkowski BF, MacHleidt T, Kirkland TA, et al. 2016. NanoLuc complementation reporter optimized for accurate measurement of protein interactions in cells. ACS Chem Biol 11: 400-408. doi:10.1021/acschembio.5b00753

England CG, Ehlerding EB, Cai W. 2016. NanoLuc: a small luciferase is brightening up the field of bioluminescence. Bioconjug Chem 27: 1175-1187. doi:10.1021/acs.bioconjchem.6b00112

Eyler DE, Green R. 2011. Distinct response of yeast ribosomes to a miscoding event during translation. RNA 17: 925-932. doi:10 $.1261 /$ rna.2623711

Eyler DE, Wehner KA, Green R. 2013. Eukaryotic release factor 3 is required for multiple turnovers of peptide release catalysis by eukaryotic release factor 1. J Biol Chem 288: 29530-29538. doi:10 $.1074 / j b c . M 113.487090$

Freistroffer DV, Kwiatkowski M, Buckingham RH, Ehrenberg M. 2000. The accuracy of codon recognition by polypeptide release factors. Proc Natl Acad Sci 97: 2046-2051. doi:10.1073/pnas .030541097

Frolova LY, Simonsen JL, Merkulova TI, Litvinov DY, Martensen PM, Rechinsky VO, Camonis JH, Kisselev LL, Justesen J. 1998. Functional expression of eukaryotic polypeptide chain release factors 1 and 3 by means of baculovirus/insect cells and complex formation between the factors. Eur J Biochem 256: 36-44. doi:10 .1046/j.1432-1327.1998.2560036.x

Frolova LY, Tsivkovskii RY, Sivolobova GF, Oparina NY, Serpinsky OI, Blinov VM, Tatkov SI, Kisselev LL. 1999. Mutations in the highly conserved GGQ motif of class 1 polypeptide release factors abolish ability of human eRF1 to trigger peptidyl-tRNA hydrolysis. RNA 5: 1014-1020. doi:10.1017/S135583829999043X

Frolova LY, Merkulova TI, Kisselev LL. 2000. Translation termination in eukaryotes: polypeptide release factor eRF1 is composed of functionally and structurally distinct domains. RNA 6: 381-390. doi:10 .1017/S135583820099143X

Goldman DH, Kaiser CM, Milin A, Righini M, Tinoco I, Bustamante C. 2015. Mechanical force releases nascent chain-mediated ribosome arrest in vitro and in vivo. Science 348: 457-460. doi:10 $.1126 /$ science. 1261909

Hellen CUT. 2018. Translation termination and ribosome recycling in eukaryotes. Cold Spring Harb Perspect Biol doi:10.1101/cshper spect.a032656

Hoernes TP, Clementi N, Juen MA, Shi X, Faserl K, Willi J, Gasser C, Kreutz C, Joseph S, Lindner $\mathrm{H}$, et al. 2018. Atomic mutagenesis of stop codon nucleotides reveals the chemical prerequisites for release factor-mediated peptide release. Proc Natl Acad Sci 115: E382-E389. doi:10.1073/pnas.1714554115

Ivanov A, Mikhailova T, Eliseev B, Yeramala L, Sokolova E, Susorov D, Shuvalov A, Schaffitzel C, Alkalaeva E. 2016. PABP enhances release factor recruitment and stop codon recognition during translation termination. Nucleic Acids Res 44: 7766-7776. doi:10.1093/ nar/gkw635

Jha S, Komar AA. 2011. Birth, life and death of nascent polypeptide chains. Biotechnol J 6: 623-640. doi:10.1002/biot.201000327
Kashima I, Yamashita A, Izumi N, Kataoka N, Morishita R, Hoshino S, Ohno M, Dreyfuss G, Ohno S. 2006. Binding of a novel SMG-1-Upf1-eRF1-eRF3 complex (SURF) to the exon junction complex triggers Upf1 phosphorylation and nonsensemediated mRNA decay. Genes Dev 20: 355-367. doi:10.1101/ gad.1389006

Kolb VA, Makeyev EV, Spirin AS. 1994. Folding of firefly luciferase during translation in a cell-free system. EMBO J 13: 3631-3637. doi:10.1002/j.1460-2075.1994.tb06670.x

Korostelev A, Asahara H, Lancaster L, Laurberg M, Hirschi A, Zhu J, Trakhanov S, Scott WG, Noller HF. 2008. Crystal structure of a translation termination complex formed with release factor RF2. Proc Natl Acad Sci 105: 19684-19689. doi:10.1073/pnas .0810953105

Korostelev A, Zhu J, Asahara H, Noller HF. 2010. Recognition of the amber UAG stop codon by release factor RF1. EMBO J 29: 2577-2585. doi:10.1038/emboj.2010.139

Lashkevich KA, Shlyk VI, Kushchenko AS, Gladyshev VN, Alkalaeva EZ, Dmitriev SE. 2020. CTELS: a cell-free system for the analysis of translation termination rate. Biomolecules 10: 911. doi:10.3390/ biom10060911

Laurberg M, Asahara H, Korostelev A, Zhu J, Trakhanov S, Noller HF. 2008. Structural basis for translation termination on the $70 \mathrm{~S}$ ribosome. Nature 454: 852-857. doi:10.1038/nature07115

Matheisl S, Berninghausen O, Becker T, Beckmann R. 2015. Structure of a human translation termination complex. Nucleic Acids Res 43: 8615-8626. doi:10.1093/nar/gkv909

Mikhailova T, Shuvalova E, Ivanov A, Susorov D, Shuvalov A, Kolosov PM, Alkalaeva E. 2017. RNA helicase DDX19 stabilizes ribosomal elongation and termination complexes. Nucleic Acids Res 45: 1307-1318. doi:10.1093/nar/gkw1239

Mort M, Ivanov D, Cooper DN, Chuzhanova NA. 2008. A meta-analysis of nonsense mutations causing human genetic disease. Hum Mutat 29: 1037-1047. doi:10.1002/humu.20763

Nakamura Y, Ito K. 1998. How protein reads the stop codon and terminates translation. Genes Cells 3: 265-278. doi:10.1046/j.13652443.1998.00191.x

Ng MY, Zhang $H$, Weil A, Singh $V$, Jamiolkowski R, BaradaranHeravi A, Roberge $M$, Jacobson A, Friesen W, Welch $E$, et al. 2018. New in vitro assay measuring direct interaction of nonsense suppressors with the eukaryotic protein synthesis machinery. ACS Med Chem Lett 9: 1285-1291. doi:10.1021/acsmedchemlett $8 \mathrm{~b} 00472$

Pierson WE, Hoffer ED, Keedy HE, Simms CL, Dunham CM, Zaher HS. 2016. Uniformity of peptide release is maintained by methylation of release factors. Cell Rep 17: 11-18. doi:10.1016/j.celrep.2016 .08 .085

Prokhorova I, Altman RB, Djumagulov M, Shrestha JP, Urzhumtsev A, Ferguson A, Chang CWT, Yusupov M, Blanchard SC, Yusupova G, et al. 2017. Aminoglycoside interactions and impacts on the eukaryotic ribosome. Proc Natl Acad Sci 114: E10899-E10908. doi:10.1073/pnas.1715501114

Shao S, Murray J, Brown A, Taunton J, Ramakrishnan V, Hegde RS. 2016. Decoding mammalian ribosome-mRNA states by translational GTPase complexes. Cell 167: 1229-1240.e15. doi:10 .1016/j.cell.2016.10.046

Svidritskiy E, Ling C, Ermolenko DN, Korostelev AA. 2013. Blasticidin S inhibits translation by trapping deformed tRNA on the ribosome. Proc Natl Acad Sci 110: 12283-12288. doi:10.1073/pnas .1304922110

Wangen JR, Green R. 2020. Stop codon context influences genomewide stimulation of termination codon readthrough by aminoglycosides. eLife 9: e52611. doi:10.7554/eLife.52611

Weixlbaumer A, Jin H, Neubauer C, Voorhees RM, Petry S, Kelley AC, Ramakrishnan V. 2008. Insights into translational termination from 


\section{Susorov et al.}

the structure of RF2 bound to the ribosome. Science 322: 953 956. doi:10.1126/science. 1164840

Wu C, Roy B, He F, Jacobson A. 2019. Nonsense suppression position effect implicates poly(A)-binding protein in the regulation of translation termination. SSRN Electron J. doi:10.2139/ssrn.3483671

Youngman EM, He SL, Nikstad LJ, Green R. 2007. Stop codon recognition by release factors induces structural rearrangement of the ribosomal decoding center that is productive for peptide release. Mol Cell 28: 533-543. doi:10.1016/j.molcel.2007.09.015
Zavialov AV, Buckingham RH, Ehrenberg M. 2001. A posttermination ribosomal complex is the guanine nucleotide exchange factor for peptide release factor RF3. Cell 107: 115-124. doi:10.1016/ S0092-8674(01)00508-6

Zhouravleva G, Frolova L, Le GoffX, Le Guellec R, Inge-Vechtomov S, Kisselev L, Philippe M. 1995. Termination of translation in eukaryotes is governed by two interacting polypeptide chain release factors, eRF1 and eRF3. EMBO J 14: 4065-4072. doi:10.1002/j.14602075.1995.tb00078.x 

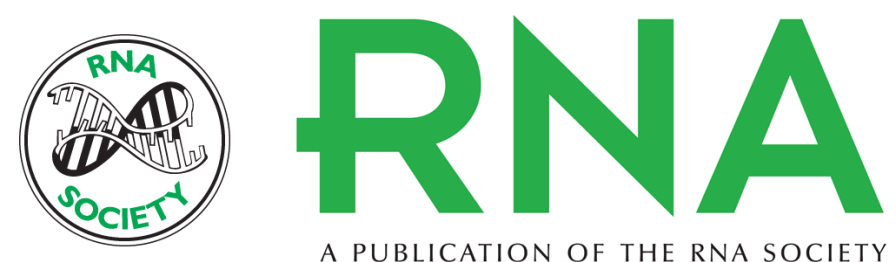

A PUBLICATION OF THE RNA SOCIETY

\section{Termi-Luc: a versatile assay to monitor full-protein release from ribosomes}

Denis Susorov, Shawn Egri and Andrei A. Korostelev

RNA 2020 26: 2044-2050 originally published online August 14, 2020

Access the most recent version at doi:10.1261/rna.076588.120

References This article cites 40 articles, 14 of which can be accessed free at: http://rnajournal.cshlp.org/content/26/12/2044.full.html\#ref-list-1

Open Access Freely available online through the RNA Open Access option.

Creative This article, published in RNA, is available under a Creative Commons License

Commons (Attribution-NonCommercial 4.0 International), as described at

License http://creativecommons.org/licenses/by-nc/4.0/.

Email Alerting Receive free email alerts when new articles cite this article - sign up in the box at the Service top right corner of the article or click here. 